\title{
DILEMAS E IMPASSES DA RESISTÊNCIA AO AGRONEGÓCIO NO CERRADO
}

\author{
CARLOS ALBERTO FRANCO DA SILVA ${ }^{1}$
}

Universidade Federal Fluminense

\section{Introdução}

Em áreas do Cerrado, a recomposição de territórios e paisagens regionais tem sido parte integrante das transformações e impactos do sistema capitalista, em escalas internacional, nacional, regional e local. A inserção do Cerrado na divisão internacional do trabalho através do processo de industrialização da agricultura e a constituição de complexos territoriais produtivos, capitaneados pelo circuito grãos-carne, respondem, em parte, pelas transformações ali presentes. $\mathrm{O}$ papel das políticas territoriais, mudanças estruturais do padrão produtivo capitalista, ideologias geográficas de integração do território brasileiro e transformações das economias regionais são algumas das razões dos impactos de uma nova racionalidade produtiva e discursiva que se projetou em áreas do Cerrado. Diante de tais transformações, a expansão do complexo agroindustrial da cadeia soja-pecuária ou do chamado agronegócio, no âmbito do processo de abertura e consolidação da fronteira agrícola capitalista no Cerrado, está na ordem do dia da pesquisa científica da Geografia Agrária.

As preocupações acadêmicas da Geografia com a expansão do agronegócio nos biomas da Amazônia e do Cerrado têm se concentrado nos estudos da violência pública e privada contra populações tradicionais e campesinas, concentração de terras, grilagem, desmatamento, logística, urbanização sem cidadania, relação homem-natureza, modernização da agricultura, dentre outros.

${ }^{1}$ carlosfds@terra.com.br 
Há, por assim dizer, uma geografia do campesinato e outra do agronegócio, que, às vezes, parecem ser rotuladas, por alguns pesquisadores, de "esquerda" e de "direita", respectivamente. Um enfoque de destaque é a análise crítica da fronteira agrícola e do agronegócio sob a ótica do espaço e da técnica, com forte apoio na obra de Milton Santos.

Outro viés reside na análise do agronegócio sob o prisma da colonialidade-colonialismo do poder, uma frente de crítica à modernidade imposta pelos capitalistas e intelectuais europeus e americanos. Essa corrente é muito marcada pela crítica à episteme eurocêntrica. É como se o eurocentrismo se projetasse no mundo como uma força hegemônica de modo a alterar valores e modos de vida sob o viés do capitalismo.

Há outra linha de investigação da Geografia Agrária que se apoia em clássicos do marxismo, afirmando a importância política do campesinato na leitura do avanço do capitalismo no mundo rural. Destacam-se textos de Karl Marx, Lenin, Karl Kautsky, Alexander Chayanov, José de Souza Martins, Ariovaldo de Oliveira, Ruy Moreira, Octávio Ianni, dentre outros.

Diante de diversas possibilidades interpretativas, vale lembrar que, não se busca neste texto o confronto entre a "verdade territorial capitalista" com a "verdade territorial campesina". Até porque há mais contradições do que antagonismos entre ambas as verdades. Há um conflito entre elas, e não propriamente um confronto. A verdade capitalista se apropria de relação de produção não capitalistas, valores, costumes e símbolos do campesinato, mesmo que seja para ressignificá-los sob novas bases de valor. Por outro lado, a verdade territorial campesina busca romper com o capitalismo, mas utiliza de suas bases reprodutivas para práticas de permanência na terra como meio de produção, recurso natural e abrigo. Mas há os que lutam pelo fim do capitalismo. Uma situação de confronto seria o fim da propriedade privada, seja camponesa, seja burguesa. $\mathrm{O}$ conflito assinala permanências das relações sociais, mesmo que elas estejam sempre em tensão. No conflito há possibilidade de algum consenso; mas no confronto um grupo social quer sempre eliminar o outro, pois não tolera a sua existência.

Assim sendo, a opção analítica sinaliza para os conflitos acerca dos dilemas das resistências dos movimentos sociais em contraposição aos esquemas de acumulação do agronegócio.

Desse modo, a opção analítica do estudo em tela assume um caráter 
de perspectiva, que se liga às possibilidades de interpretação, conforme recomenda Nietzsche. A interpretação proposta não desconhece as possibilidades das outras leituras (pelo contrário), apesar de sempre haver conflitos de interpretações. Isso porque qualquer interpretação não é livre, pois se situa num de campo de valores específicos.

Assim posto, o viés analítico que aqui se coloca é o estudo do agronegócio e das resistências à luz das redes políticas. Tais redes sinalizam para uma arena formada por atores com estratégias definidas, que se confronta com valores e interesses de grupos diversos, que também definem suas redes políticas de resistências e afirmação de identidades territoriais.

A existência das redes políticas aponta para conflitos de territorialidades na Amazônia e no Cerrado. Uma das personagens desses conflitos são as corporações do agronegócio. Grupos como CARGILL, BUNGE, DREYFUS, AMAGGI e ADM são os principais agentes de des(re)territorialização de grupos sociais e reorganização espacial, dada a dimensão multifuncional e a multilocalização de seu sistema de objetos e de ações em escalas geográficas diversas.

Se pensarmos na corporação AMAGGI, quinto maior grupo de comercialização de grãos do país, pode-se afirmar, com base nas considerações de Hanna Arendt (2009:258-9), que a ação política da corporação possui quatro elementos indissociáveis, a saber: 1) o fim que ela persegue; 2) o objetivo que tem em mente e pelo qual se orienta; 3) o significado que se revela no curso da ação e 4) o princípio que a coloca em movimento, isto é, a convicção compartilhada por um grupo de pessoas (2009:258-9).

Grupo AMAGGI, a partir da figura de Blairo Maggi, aponta para o fato de estarmos diante de um ator-rede ou corporação-rede que estabelece estratégias-redes, troca de recursos de poder diante de objetivos compartilhados, definição de decisões que configuram o território corporativo (cidade de Sapezal, por exemplo) e diversos planos de visibilidade do poder e de resistências sinalizadas por movimentos sociais. O fim em jogo é a reprodução ampliada do capital no âmbito do agronegócio da soja em áreas do cerrado. Para tanto, os objetivos se direcionam para a eliminação de obstáculos sociais aos interesses da corporação, através de estratégias-redes. O significado da ação aponta para desmatamento, concentração fundiária, controle do aparelho político, 
alianças com outras tradings, legitimação de um modelo de "desenvolvimento", mudanças das leis ambientais e requalificação do território. A convicção fica por conta das possibilidades reais de acumulação de capital, apesar das resistências.

A estratégia-rede do Grupo AMAGGI implica compartilhar interesses que se inscrevem em campo de ação política, conforme assinala Arendt. A dimensão territorial dispersa e articulada da base produtiva sinaliza lógicas coerentes de definição do campo de ação da rede da corporação. Uma demanda da estratégia-rede diz respeito à manutenção de práticas, flexibilização das ações e pertencimento territorial através de aparelhos discursivo-ideológicos. A estratégia-rede orienta e ativa as relações entre atores; define um conteúdo comum (expansão da soja) e interesses particulares e assegura vantagens competitivas. A estratégia-rede viabiliza ainda acesso a recursos complementares à corporação (informação, capital, tecnologia, etc.) e legitimidade institucional junto ao agronegócio da soja. Daí as parcerias e alianças de que o Grupo AMAGGI participa.

A arena politica da corporação orienta e articula-se a diversos atores, tais como empresas, sindicatos, prefeituras, associações, federações, ONG's, partidos políticos e instituições no âmbito de interesses coletivos, apropriando-se das vantagens da própria rede constituída. A estratégia-rede do Grupo AMAGGI se relaciona ao sentido de sua rede política. Há uma rede de atores com os quais a corporação mantém vínculos institucionais, tais como a Associação dos Produtores de Soja de Mato Grosso (Aprosmat), universidade e centros de pesquisa e fundações de pesquisa. Essas articulações são estratégicas e apontam para a logística do Grupo AMAGGI.

Mas há resistências políticas a essas linhas de forças hegemônicas do agronegócio. É esse o ponto de partida deste artigo: chamar a atenção para o enfoque das redes políticas de resistências ao agronegócio. Vale lembrar que este artigo é parte integrante do projeto de pesquisa financiado pelo Programa Bolsa Produtividade em Pesquisa do CNPq-2009-2012, intitulado "As redes políticas das corporações do agronegócio da soja em áreas da Amazônia”. 


\section{O campo de forças das resistências ao agronegócio}

Os pequenos produtores e as chamadas populações tradicionais dispersas em áreas da Floresta Equatorial e do Cerrado são os atores-rede que resistem às práticas socioespaciais das corporações, através de vários movimentos sociais (Movimentos dos Sem-Terra, MST, Movimentos dos Trabalhadores Acampados e Assentados, MTA, Movimentos dos Atingidos por Barragens, MAB, dentre outros). Tais movimentos se organizam em verdadeiras redes políticas em que o interesse comum de lutar contra o capital pode unir grupos dissidentes ou não, quando se estabelecem os embates contra o agronegócio. As parcerias entre esses movimentos sociais, CPT (Comissão Pastoral da Terra), FETAG (Federação dos Trabalhadores na Agricultura), professores e estudantes universitários, ONG's, sindicatos e partidos políticos constituem o recurso de poder que anuncia redes políticas de resistências ao agronegócio, sobretudo contra a grilagem, o trabalho escravo, o despejo, as desapropriações e assassinatos, em áreas de expansão da soja, pecuária, cana, algodão e eucalipto.

$\mathrm{O}$ que se percebe é que, apesar de os interesses serem diversos e particulares, a ação coletiva ratifica, legitima e viabiliza a realização de objetivos específicos. A CPT visa defender a reforma agrária e expandir a fé católica. Alguns professores e universitários veem na defesa do campesinato um canal de expressão da ideologia socialista em contraposição ao capitalismo. Os partidos políticos de esquerda parecem defender a reforma agrária e os ideais socialistas, apesar de haver contradições entre ideias e ação politica, quando o partido assume algum grau de hegemonia no cenário nacional. Exemplo expressivo é o Partido dos Trabalhadores. Apesar da defesa da reforma agrária, o Governo do Presidente Lula avançou muito pouco no apoio à distribuição de terras e à pequena produção familiar. As ONG's possuem interesses contraditórios que escapam ao escopo deste trabalho. Ás vezes, elas estão do lado dos capitalistas e, em outras situações, do lado das populações tradicionais. De qualquer modo, são as parcerias entre esses atores que se constituem recursos de poder na luta contra a expansão da fronteira capitalista da soja. Tais alianças lutam por direito à existência de populações tradicionais. Como direito é poder, a luta se constitui em estratégias de afirmação de poder, na forma de visibilidade de identidades territoriais e representações simbólico-culturais dos grupos sociais envolvidos no conflito com os 
atores representativos do grande capital.

A rede política assim constituída revela estratégia de coordenação das decisões políticas, visto que as ações se inserem em escalas geográficas diversas. O Movimento dos Sem-Terra é um bom exemplo, visto que suas alianças com professores, alunos, sindicatos, ONG's, federações, CPT, partidos políticos, agricultores e intelectuais atingem o território brasileiro. A rede política do MST veicula instruções, disciplina politico-ideológica, regras, preceitos e valores que são compartilhados pelas pessoas que fazem parte dela. De fato, a natureza da rede do MST é política e capturada por diversos atores quando animada pelas ações que o movimento realiza, de modo a ativar pontos no território nacional onde há disputa pela terra. Enfim, as redes de resistência permitem o intercâmbio e a negociação dos interesses em jogo, de modo a distribuir custos e benefícios para que cada participante cumpra os compromissos contraídos, mesmo que haja diferenças de linhas de ação política entre os participantes da rede.

No caso do MST, as redes políticas sinalizam estratégias em torno da Reforma Agrária, enquanto parte de um projeto de transformação da sociedade em direção a um modo de produção socialista. As ocupações realizadas pelo MST, para fins de implantação de assentamentos rurais, são o principal fato político que anuncia a permanência da questão agrária no Brasil. Todavia, vale lembrar que, as contradições sociais também se apresentam no âmbito dos assentamentos rurais, em áreas de avanço do agronegócio no Cerrado. Há assentamentos onde a terra é arrendada para o agronegócio. Há também assentados sem o sentido coletivo do uso da terra. Uso dos lotes rurais para fins de residência de fim de semana e para a venda ilegal da terra também ocorre. Entretanto, a grande maioria dos assentados busca cumprir a função social da terra. Mas há diversas dificuldades, após a fase de ocupação jurídica das terras. Nesse ponto, vale lembrar que a legalização dos lotes rurais é um dos maiores problemas de permanência do produtor na terra, depois da fase de acampamento.

A localização do assentamento, a qualidade dos solos e da água, o licenciamento ambiental, a falta de apoio técnico e financeiro e de tradição com a terra podem ser obstáculos à manutenção dos pequenos produtores. A realidade de boa parte dos assentados é a dependência de transferência de renda do poder público federal, tais como Bolsa Família e aposentadoria. A renda decorrente da agropecuária é baixa e a pressão de grupos sociais mais capitalizados é imensa. Mas os avanços dos 
assentamentos na constituição de áreas de desenvolvimento local já são uma realidade. Há indicadores demográficos dos dois últimos Censos do IBGE que mostram aumento da população rural em alguns municípios onde a luta pela terra resultou em assentamentos rurais. $O$ fim do campesinato parece não se afirmar, apesar das teorias fatalistas que se destacam, desde o século XIX, mesmo entre alguns teóricos marxistas.

A luta por um modelo de produção agroecológica para os pequenos produtores é uma das estratégias que se coloca como alternativa ao agronegócio. Em alguns casos, a urbanização da população rural também se revela como uma via de manutenção da pequena agricultura familiar promovida pelas populações tradicionais. As articulações em redes urbanas alteram valores e hábitos, mas podem desvelar estratégias-rede de resistências ao agronegócio.

De qualquer modo, um dos maiores desafios dos movimentos sociais é a ideologia geográfica a partir do discurso da sustentabilidade em disputa pelas corporações. Para elas, sustentabilidade é a metáfora para legitimar o "progresso" com "responsabilidade social". No Cerrado, maior área potencial para o agronegócio do Brasil, os capitalistas se apropriam do discurso de preservação da natureza, a fim de afirmar um pertencimento aos reclamos ambientais impostos por movimentos ambientalistas e a sociedade civil, em geral.

Os capitalistas do agronegócio da soja forjam um discurso ambiental através da defesa da Pegada Ecológica, como indicador de sustentabilidade ambiental para medir e gerenciar o uso de recursos naturais (terra e água) e estilo de vida, produtos e serviços através da economia. A proposta de uma Economia Verde também se apresenta como mecanismo de mercantilização da natureza sob o discurso de responsabilidade socioambiental. A proposta de substituição de tecnologias "sujas" por tecnologias ditas "limpas" não é acompanhada por mudanças socioeconômicas do modo de produção capitalista.

O discurso da "necessidade de aumentar a produção de alimentos para o mundo" escamoteia a problemática da redução de áreas de produção da pequena agricultura familiar de alimentos e da desigual distribuição da produção agropecuária, cujo resultado se manifesta na fome a que estão submetidos milhões de indivíduos no mundo.

Uma das questões que se coloca para o agronegócio é unir os 
reclamos da sociedade por sustentabilidade socioambiental, a acumulação ampliada dos lucros e as políticas públicas. A ação dos movimentos ambientalistas e de populações tradicionais interfere nos interesses das corporações e grandes produtores do Cerrado. Apesar de o Estado ser capitalista, as resistências se fazem presentes nas políticas públicas. As restrições impostas pela Área de Reserva Legal dos biomas, o Zoneamento Ecológico-Econômico e a criação de Territórios Indígenas, Reservas Extrativistas e Unidades de Conservação e controle de poluentes direcionam as empresas para um processo chamado de "green wash", de modo a internalizar vantagens competitivas no âmbito de uma mercantilização da sustentabilidade socioambiental. Assim sendo, alguns setores industriais defendem a manutenção da biodiversidade com políticas em prol das florestas, para fins de uso do potencial dos recursos naturais no consumo urbano. Na indústria canavieira, há pesquisas para a redução do vinhoto transportado e jogado em rios. Mas o Cerrado ainda é um dos principais biomas fornecedores de carvão usado para produzir ferro e aço no Brasil. A relação entre trabalho escravo e siderurgia avançou no Cerrado e na Caatinga, nos últimos dez anos, segundo dados da ONG Repórter Brasil.

No que diz respeito ao trabalho escravo, informações da CPT, para o período de 2000 e 2010, revelam denúncias de trabalho escravo nas lavouras de soja do Cerrado. Foram 2.883 casos para um total de 26.800 . Isto é, a produção de soja representa $10,7 \%$ das denúncias de trabalho escravo. Mato Grosso, Maranhão e Tocantins são locais de maior registro de casos (Dados obtidos do projeto PIBIC-CNPq do bolsista Vitor de Moura Lima). De acordo com Cosandey (2011, p.146), o trabalho escravo na lavoura de soja se situa tanto na limpeza de antigos pastos quanto na derrubada da mata.

Em suma, apesar das dificuldades, são as lutas em defesa de novos modelos de vida que empurram as empresas para um discurso ambiental em termos de efetiva mudança de padrão produtivo, ou apenas, enquanto discurso. A defesa do desenvolvimento sustentável tem sido acompanhada por práticas pouco sustentáveis e não sustentáveis pelas corporações, que se articulam em redes políticas para assumir o controle dos recursos naturais. Mas é preciso reconhecer pequenos avanços no padrão produtivo industrial em direção à redução de impactos ambientais. Se tal postura implica redução de custos de produção, a sustentabilidade é bem-vinda. $\mathrm{O}$ que está no centro é sempre a reprodução ampliada dos lucros. As 
corporações precisam dar uma resposta à sociedade civil, mesmo que seja parcial. Isso faz parte do seu marketing ambiental.

Nesse ponto, vale destacar que, a questão da segurança alimentar parece não fazer parte dos interesses das corporações, preocupadas em expandir um modo global e padronizado de se alimentar. A criação de um banco de sementes, que estão desaparecendo por conta da monocultura de commodities, é uma boa estratégia de resistência que vem sendo aplicada na Índia pela ativista ambiental Vandana Shiva.

Mas a luta pela afirmação do poder discursivo do agronegócio está em diversas frentes, tais como no fomento aos "dias de campo", evento em que são apresentadas as inovações no modo de produzir e estratégias de defesa dos interesses de produtores e corporações diante dos limites ambientais da legislação e da ação dos ambientalistas e movimentos sociais.

Ao contrário do que pensam alguns intelectuais da Geografia Agrária, os capitalistas do agronegócio não criam apenas um lugarmercadoria, uma terra de negócio. As estratégias discursivas e as ações sociais junto às localidades, através de políticas assistencialistas, apoio à cultura e ao lazer, fazem parte da constituição de um lugar-habitat do capital, para fins de afirmação de uma imagem de pertencimento territorial com os lugares. Logo, é preciso repensar algumas afirmações, tais como o fato de o capitalista ver os lugares apenas como base material, espaço vazio. O cotidiano, o espaço vivido, as políticas públicas e os conflitos que se manifestam nos lugares são percebidos pelos empresários, quando da decisão de investimentos locais. O discurso dos movimentos sociais, que afirma a despreocupação dos capitalistas com os lugares alvos de seus interesses, não me parece correto. Há sempre uma leitura prévia dos lugares, mesmo que seja para destruir territórios pré-existentes. No caso dos Cerrados, as comunidades locais são incorporadas no discurso e nas estratégias das corporações, mesmo que isso se mostre de modo excludente ou via inserção precária nos mecanismos de acumulação de capital.

Além disso, a história do lugar pode ser acionada, para fins de afirmação do ideário de modernidade veiculado pelo agronegócio e de estratégias de pertencimento com os lugares. Um bom exemplo é Blairo Maggi, sulista, ex-governador de Mato Grosso e ex-presidente do Grupo AMAGGI. Em um dos seus discursos, Blairo declara ser um "bandeirante 
mato-grossense". É preciso forjar um sentimento de pertencimento nos lugares ainda que provisório e contingente.

No tocante às representações simbólicas, Blairo Maggi se legitima como um "novo bandeirante", figura mítica, que é recuperada para dar viabilidade aos ideais de modernidade que implica o avanço da soja. Blairo Maggi e soja são símbolos de "desenvolvimento", da revolução do começo de uma nova fase da história de Mato Grosso e do deslocamento de práticas socioculturais tradicionais, que são traduzidas como atraso. De fato, Blairo se utiliza de um imaginário, no sentido de um deslocamento de símbolo já disponível e investido de outra significação, de modo a passar do virtual ao real para existir, conforme pensamento de Castoriadis (1982, p.154). O simbolismo pressupõe o imaginário, a fim de ver em uma coisa o que ela não é. Junto ao simbolismo de bandeirante de Blairo, residem os discursos da modernidade.

Os discursos desenvolvimentistas funcionam como "verdades", que detêm poderes específicos ao se sobrepor a outros discursos. $\mathrm{O}$ discurso põe em jogo o poder e o desejo, conforme assinala Foucault (2004,p.21). Blairo anuncia um tipo de discurso enquanto instrumento de controle e de poder. Parafraseando Foucault (2004:p.233), diríamos que Blairo utiliza o ideário de desejo do progresso que as pessoas esperam para Mato Grosso. Ele explora a tentação de acreditar que o avanço da fronteira agrícola capitalista é o caminho para a melhoria das condições de vida. De fato, para uma parcela da população as melhorias realmente acontecem. Mas não é isso que está em jogo. Na economia política do discurso de Blairo, há sistemas de coerção, exclusão e legitimação dos enunciados que prega em defesa da expansão da soja. Nesse sentido, o discurso de Blairo acaba enquadrando os movimentos sociais de revolta ao agronegócio como inimigos do "desenvolvimento". Além disso, não é à toa que, em vários lugares onde a soja ainda não aparece, as pessoas esperam a sua chegada. $\mathrm{E}$, ao mesmo tempo, nos lugares em que a soja se consolida, as estratégias e objetivos dos movimentos sociais dividem opinião entre as pessoas.

No plano da recomposição da paisagem geográfica, as áreas de Cerrado alteradas pelo agronegócio, o que significa desmatamento e destruição da fauna e flora, revelam um espaço projetado, construído e vivido por diversas comunidades distribuídas em áreas de campo e cidades. A sensação que se tem ao olhar a paisagem do agronegócio é a de um contínuo espacial em face do grau de integração entre campo e cidade. As 
cidades do agronegócio da soja têm seu espaço urbano organizado para atender à demanda da produção agropecuária e, por sua vez, são afetadas pelos ritmos de produção de commodities e preços internacionais da cadeia grãos-carne.

Ao olhar as cidades e o uso intensivo das áreas agrícolas, cria-se a sensação de uma unidade produtiva acompanhada do discurso desenvolvimentista e do progresso. Nas cidades do agronegócio da soja no Cerrado, a história é percebida pelos habitantes entre antes e depois das transformações do agronegócio. A criação de empregos nas cidades, o discurso da "melhoria dos indicadores sociais", a implantação de empreendimentos industriais, centros de pesquisa, armazéns e melhorias da logística de transporte contribuem para legitimar junto à população a importância do agronegócio. Quem se coloca contra é visto como inimigo do "progresso" e "estrangeiro", já que não vivia em tais cidades antes do "agronegócio moderno" chegar. Assim sendo, a própria população urbana se coloca como parte da rede política de resistência criada pelos atores hegemônicos para legitimar o agronegócio. Apesar da existência de áreas da cidade do agronegócio, onde se distribuem casas precárias, invasões dos sem-teto, desempregados e ausência de serviços básicos, de um modo geral, as populações urbanas do Cerrado fazem política de afirmação do agronegócio. Nesse grupo participam professores universitários, empresários, trabalhadores, donas de casa etc. Consolida-se uma identidade e uma força cultural de resistência aos ambientalistas e movimentos sociais.

O desafio para os movimentos sociais é imenso: qual é a alternativa para essas cidades que dependem do agronegócio? Agricultura familiar agroecológica? Expropriação dos meios de produção de grandes produtores e industriais? O que significa uma gestão democrática e planificada dos recursos naturais pelos trabalhadores em geral? Qual é o modelo de sustentabilidade ambiental urbana com justiça social e garantia das diferenças entre os indivíduos? O que significa um modelo de equidade e justiça para economias urbanas locais? Nós estamos pensando em modelo ou modelos alternativos ao capitalismo? Os modelos propostos são tirânicos ou democráticos? Se for democrático, quais são o sentido e valor da democracia que defendem os movimentos sociais? A democracia conservadora pode ser tão tirânica como a ditadura. A constituição de partidos revolucionários da classe dos trabalhadores do campo e da cidade também pode ser autoritária. As populações urbanas serão chamadas para 
decidir sobre seu futuro? O que os movimentos sociais acreditam ser o melhor para as populações urbanas e rurais é o que elas querem como modo de vida? Devemos impor um novo contrato social que equacione a relação entre vontade geral e vontade particular? Que valores isso significa, de fato, para os movimentos sociais?

De minha parte, não saberia dizer qual é o melhor caminho.

Durante a Conferência das Nações Unidas, chamada Rio+20, as tensões entre uma defesa capitalista da Economia Verde e as alternativas ambientais sustentáveis apresentadas por movimentos sociais foram marcas visíveis dos desafios em curso. Os conflitos entre a racionalidade territorial do agronegócio e a racionalidade territorial campesina foi um dos destaques da Conferência.

Do meu ponto de vista, defendo a transição do agronegócio para formas de ocupação e manejo dos solos fundamentais à valorização da biodiversidade dos lugares e manejos agroecológicos. Isso porque já está provado que um agroecossistema organizado em bases agroecológicas possibilita articulações funcionais com os ecossistemas naturais nos quais estão inseridos. Nesse caso, a força dos lugares se coloca por meio das dinâmicas sociais, em termos de saberes e inovação, que atendam a requisitos locais. A agroecologia implica manutenção de agroecossistemas complexos, o que significa diversificação de culturas, rotação e sucessão de espécies. Quando se pensa em sustentabilidade ambiental, a agroecologia possibilita redução do uso de energia fóssil e de água. $\mathrm{O}$ manejo da agricultura sugere ainda conservar a fertilidade dos solos sem uso de insumos externos e resistência à erosão dos solos. Assim sendo, o maior desafio à sustentabilidade socioambiental não é técnico-cultural, mas político.

O impacto do agronegócio sinaliza para perda da cultura camponesa e introdução de soluções universais para a agricultura baseadas em pacotes da Revolução Verde. O verde aqui funciona como elemento simbólico de legitimação e pertencimento à afirmação de novo modo de produzir no espaço agrícola.

De qualquer modo, a questão central está posta: quais são as condições para superação do agronegócio pela Agroecologia, quando se pensa a organização da sociedade capitalista globalizada por forte domínio da população urbana vis-à-vis a população camponesa? Ainda não sei qual 
seria a melhor resposta.

No plano teórico, há a proposta de um metabolismo agrário, ou seja, a aplicação do metabolismo socioecológico a agroecossistemas, para fins de sustentabilidade agrícola. De acordo com o professor Manuel Gonzalez de Molina, pesquisador da Universidade Autônoma do México, e autor do livro "Metabolismo, naturaleza e historia: hacia uma teoria de las transformaciones socioecológicas", a abordagem metabólica na agricultura permite uma alternativa produtiva que leva em conta a crise ambiental, as escalas geográficas (do cultivo, da propriedade rural até aos mercados globais). De fato, a proposta metabólica se afirma como ferramenta política à Agroecologia, de modo a apontar para os movimentos sociais algumas linhas de ação e pontos críticos do sistema agroalimentar. Isso porque a metodologia metabólica busca descrever os aspectos que envolvem desde a lavoura até a mesa do consumidor. Nessa trajetória, verificam-se problemas de insustentabilidade agroalimentar, os atores hegemônicos que se beneficiam do modelo, e sinalizam-se para políticas públicas agroecológicas.

Diante de tantas questões, alternativas, avanços, recuos e impasses para os movimentos sociais, os capitalistas do agronegócio se antecipam e redirecionam suas estratégias-rede. As corporações já estão mobilizadas a dar uma resposta à sociedade, em geral, e às redes políticas de resistência aos seus interesses, em particular, mesmo que seja pela força. Isso porque além do poder discursivo-ideológico da sustentabilidade e responsabilidade social, há o exercício coercitivo do poder através da violência no campo. Informações da Comissão Pastoral da Terra alertam para os casos de assassinatos, expulsão e escravidão de produtores rurais e populações tradicionais, em geral.

Se situarmos tal debate no plano teórico, diríamos que a resistência promovida pelos movimentos sociais é resultado de relações de poder engendradas pelo agronegócio. É uma possibilidade de criar espaços de luta e de transformação social. Sendo também poder, a resistência deve ser inventiva, móvel e produtiva, vir "de baixo" e se distribuir estrategicamente, conforme assinala Foucault (2004: 240-42), no livro “ Microfísica do Poder".

Assim sendo, os movimentos sociais têm uma natureza coextensiva e contemporânea às relações de poder no âmbito do capitalismo, pois é sempre possível modificar a dominação em determinadas condições a que 
ficam submetidos grupos sociais diversos. De certa maneira, a resistência ao agronegócio desvela identidades (Povos do Cerrado, Povos da Floresta), ideologias, discursos, geopolítica singular, normatização, estratégias e rebatimentos territoriais, que se afirmam na constituição de reservas extrativistas, luta por território quilombolas, demarcação de terras indígenas e assentamentos agrários, criação de Unidades de Conservação, dentre outras conquistas de direitos e/ou poder.

A valorização das identidades comunitárias e a formação de redes comunitárias, para fins de distribuição e comercialização de produtos, são acompanhadas pela defesa de saberes tradicionais destinados à agroecologia. A resistência também se verifica nas festas, ritos e práticas educacionais que anunciam a existência de um rural transmissor de valores geracionais. Daí os esforços na manutenção das raízes, memória e heranças culturais das populações tradicionais como estratégia de resistência e valorização de identidades territoriais, cuja racionalidade e valor da natureza estão contrários à racionalidade imposta pelo agronegócio. A luta pela terra é o acesso à justiça e ao reconhecimento de viver na diferença cultural através de modos de vida alternativos ao capitalismo (LEITE e SANTOS, 2010).

Dentre as redes políticas de resistência que defendem a biodiversidade do Cerrado e o uso sustentável do bioma, destaca-se a Rede Cerrado. Criada em 1992, ela integra mais de 300 entidades políticas envolvidas com a defesa socioambiental do Cerrado, tais como indígenas, trabalhadores rurais, quilombolas, geraizeiros, quebradeira de cocos, pescadores, ONG,s nacionais e internacionais, associação de trabalhadores rurais, cáritas diocesana, Centro de Desenvolvimento Agroecológico do Cerrado (CEDAC), Centro de Cooperativa Agroextrativista do Maranhão, Fundação Pró-Cerrado, Centro de Movimentos Populares do Vale do Jequitinhonha, Centro de Estudos e Exploração Sustentável do Cerrado etc. Há uma coordenação administrativa formada pelo Centro de Agricultura Alternativa do Norte de Minas Gerais, em Montes Claros, e o Grupo de Mobilização dos Povos Indígenas do Cerrado. A maior preocupação da rede é enfrentar as estratégias do agronegócio em áreas de expansão da fronteira agrícola e/ou áreas de fronteira consolidada.

Outra rede política importante é a da Via Campesina, que é uma organização internacional de pequenos e médios agricultores, criada em 1992, na Nicarágua no contexto do Congresso da União Nacional de 
Agricultores e Pecuaristas (Unión Nacional de Agricultores y GranaderosUNAG). As ações políticas destacam estratégias de defesa da soberania alimentar, biodiversidade, reforma agrária, ocupações de terras, crédito e dívida externa, tecnologia, participação das mulheres, entre outros. A rede política é formada, no Brasil, pelo MST, MPA-Movimento dos Pequenos Agricultores, MAB- Movimento dos Atingidos por Barragens, MMCMovimento de Mulheres Camponesas, FEAB-Federação dos Estudantes de Agronomia do Brasil, CPT, PJR-Pastoral da Juventude Rural, ABEEFAssociação Brasileira dos Estudantes de Engenharia Florestal, CIMIConselho Indigenista Missionário, pescadores artesanais. A Via Campesina busca articulação e fortalecimento dessas parcerias constituídas, de modo a promover linhas de ações, através de protestos contra empresas do agronegócio, transgenia e capital financeiro global, e defesa de sistema alimentar local e modos agroecológicos de produção agroalimentar.

Todavia, a luta por direitos, às vezes, se faz através de coalizões políticas entre sindicato de trabalhadores rurais, ONG's e corporações, como é o caso da Moratória da Soja. A moratória da soja é mais um momento em que uma rede política se estabelece, a partir das resistências e pressões sociais. Em abril de 2006, o documento do Greenpeace, "Comendo a Amazônia", alertava para o fato de a indústria internacional do setor agroalimentar estar articulada ao desmatamento, à grilagem, ao trabalho escravo e à violência no campo. Em julho do mesmo ano, as corporações se unem em torno de uma estratégia para os impactos das denúncias junto à opinião pública. Através da ABIOVE- Associação Brasileira das Indústrias de Óleos Vegetais- e da ANEC- Associação Nacional dos Exportadores de Cereais- as corporações se comprometeram em implantar um programa de governança, que objetivasse não comercializar a soja da safra oriunda de áreas que fossem desflorestadas dentro do Bioma Amazônico, após outubro de 2006. Assinaram o acordo as empresas associadas, tais como AMAGGI, CARGILL, BUNGE, ADM, DREYFUS, ABC INCO e IMCOPA. A iniciativa tinha a duração de 2 anos e inaugurou o chamado "ambientalismo empresarial", através de normas de conduta, protocolos e acordos e regulações. Os acordos apontaram alguns impactos subsequentes: 1) acordo entre agroindústria e ambientalistas; 2) constituição de uma rede formada por corporações, movimentos sociais e ONG's (Greenpeace, IPAM, TNC e WWW Brasil, Amigos da Terra, IMAZON, IMAFLORA) e Sindicato dos Trabalhadores Rurais (LIMA, 2008). 
A rede política em questão reflete um esforço entre produtores, processadoras, fornecedores de soja e sindicato, de modo a atender os interesses dos atores que participam da coalizão. Os interesses se resumem à manutenção de nichos de mercados internacionais, em face das barreiras ambientais, e aos objetivos de criar limites à expansão da soja e aos problemas sociais dela decorrentes. As iniciativas resultaram, ainda, na criação da Associação Internacional de Soja Responsável (RTRS), sob a orientação da legislação suíça. A diretoria da RTRS é formada pelo GRUPO AMAGGI, WWWF.Brasil, ABN AMRO, Fundapaz e Solidaridad. Apesar de qualquer crítica que se possa fazer a tais coalizões políticas, vale lembrar que essas redes políticas institucionalizadas não estão deslocadas do conjunto dos conflitos e das pressões sociais decorrentes dos impactos socioambientais do agronegócio.

\section{Em direção às últimas considerações}

Em linhas gerais, a rede política dos movimentos sociais de resistência ao agronegócio da soja é territorial e dialógica, pois se afirma a partir da força dos lugares e das territorialidades ali constituídas e é por elas afetada. É também rizomática, já que o agir político demanda linhas de ação em que atores-redes são acionados nos mais dispersos lugares, de acordo com os interesses e estratégias em jogo. A configuração da rede territorial expressará o sentido das entradas e saídas de atores na rede em face dos conflitos de territorialidades, temporalidades e racionalidades distintas. Nesse ponto, tal rede política está sempre no devir, se afirmando na diferença diante dos interesses e impactos provocados pelo agronegócio. A rede política das resistências também configura um quadro de assimetria de poderes, visto que as parcerias são feitas de acordo com os recursos de poder disponíveis por cada um dos atores que da rede participam. Exemplo oportuno é a organização em rede política do MST.

Na rede política, observa-se que o poder é menos uma propriedade de algum indivíduo ou grupo social do que uma estratégia, e seus efeitos são atribuídos às disposições, às manobras, às táticas e aos funcionamentos, conforme assegura Deleuze (2005:41). A forma como o poder é exercido pelas corporações do agronegócio e pelos movimentos sociais de resistência é bem sinalizador para o campo de forças que se estabelece.

No entanto, apesar dos conflitos e tensões entre os movimentos 
sociais e o agronegócio, a rede política do agronegócio tem se afirmado e também promove estratégias individuais e coletivas mais inclinadas à busca de recursos de poder, pois são eles que permitem a dominação no encadeamento e coordenação de um ou mais atores. A organização estratégica contra os movimentos sociais é parte integrante das alianças entre latifundiários, corporações, prefeitos, sindicatos patronais etc. De fato, sempre ocorre uma distribuição dos recursos de poder entre esses atores e intermediação dos objetivos em jogo.

A rede política se revela, portanto, pela interação entre recursos de poder e representação de interesses, conforme assinala Lechner (1996, p.54). Para ele, as redes políticas são instâncias e procedimentos de coordenação horizontal e descentralizada. Configura-se, portanto, um arranjo, isto é, uma trama traçada por ordens e decisões, na qual um grupo social compartilha recursos de poder e articula interesses coletivos e particulares. O resultado é a recomposição dos lugares em novas bases territoriais e temporais.

Assim sendo, a força dos lugares parece impactada pela ideologia do desenvolvimentismo atribuído ao agronegócio e pelas alternativas colocadas pelos movimentos sociais. A mobilização dos Povos da Floresta e dos Povos do Cerrado constitui uma resposta política para a permanência de modos de vida alternativos e tradicionais. Nesse campo de forças entre grandes produtores, corporações e campesinato, o agronegócio da cadeia soja-grãos na Amazônia e no Cerrado tem avanços e recuos, em face das territorialidades que resistem à corporatização dos territórios. Porém, o processo está em curso. Daí a importância do debate acadêmico e social sobre as formas de apropriação e produção capitalista de territórios em "áreas frágeis, do ponto de vista socioambiental", mas ricas de alternativas ao ordenamento territorial das corporações e favoráveis às diversas possibilidades de vida.

\section{DILEMAS E IMPASSES DA RESISTÊNCIA AO AGRONEGÓCIO NO CERRADO}

Resumo: O objetivo deste artigo é analisar as tensões entre as redes políticas territoriais promovidas pelos representantes do agronegócio e pelos movimentos sociais de resistência, em áreas do Cerrado sob o avanço e 
consolidação do complexo agroindustrial brasileiro. A conclusão a que chegamos revela a rede política do agronegócio como uma trama de estratégias de coordenação de fluxos de comando e de decisões entre diferentes atores, que compartilham a intenção de garantir a reprodução do complexo carne-grãos. Tal arena política configura o exercício de poder e aponta para a constituição de redes políticas de resistência, que defendem novos modelos de vida sustentável ambientalmente e livre dos reclamos da acumulação ampliada de capital. Tal campo de força resulta na requalificação de territórios e paisagens preexistentes do Cerrado.

Palavras-Chave: rede politica, corporação, soja, Cerrado.

\section{DILEMMAS AND IMPASSES OF RESISTANCE TO AGRIBUSINESS IN BRAZILIAN CERRADO}

Abstract: The purpose of this article is to analyze the political territorial networks created by corporations and social movement in areas in the Amazon and Cerrado where the soy business is expanding and consolidating. The core concept of the research was to view corporations as political subjects responsible for processes of territorializing the regional production based on political networks set up to attract and subordinate localities and social groups to schemes of accumulation on national and planetary scale. The conclusion that is drawn reveals the political network of soy agribusiness in the Cerrado as a web of strategies to coordinate flows of command and decision-making among various actors equally intent on guaranteeing reproduction of the soy complex. The political arena configures the exercise of power and conflicts among actors, resulting in a redefinition of preexisting territories and scenarios in the Cerrado.

Keywords: political network, corporation, soy, Cerrado.

\section{BIBLIOGRAFIA}

ARENDT, Hannah. (2009). A promessa da Política. Rio de Janeiro: Difel. BORTOLUCI, José Henrique. (2008). Formas e categorias de pensar eurocêntrico. Revista Eletrônica de Ciências Sociais. Ano 2, Volume N.5, Dezembro de 2008. Disponível em: www.editoraufjf.com.br/revista. Acesso em 10 jul. 2012. 
CASTORIADIS, Cornelius. (1982). A Instituição imaginária da sociedade. Rio de Janeiro: Paz e Terra.

COSANDEY, José Victor Juliboni. (2011). A Cartografia da Violência no Campo em Mato Grosso. In: SILVA, Carlos Alberto Franco (org). Redes Políticas Territoriais: estratégia, conflitos e violência. Rio de Janeiro: Livre Expressão, pg.113-150.

DELEUZE, Gilles. (2005). Foucault. Lisboa: Edições 70.

FOUCAULT, Michel. 1981/2004. Microfísica do poder. Rio de Janeiro: Graal.

(2004). A ordem do discurso. São Paulo: Loyola, 2004.

LECHNER, N. (1996). Reforma do Estado e condução política. Revista Lua Nova, n.37. São Paulo: CEDEC.

LEITE, Luiza Chuva Ferrari \& SANTOS, Arthur Pereira. (2010). Um Olhar sobre as redes políticas de resistências ao agronegócio no cerrado. In: SILVA, Carlos Alberto Franco \& NASCIMENTO, Luciano Bomfim do. Redes Políticas do Agronegócio da Soja: interesse, estratégia e resistências. Rio de Janeiro: Live Expressão, pg. 103-132.

LIMA, Ivaldo. (2005). Redes Políticas Territoriais e Recomposição do Território. Tese de Doutorado. Programa de Pós-Graduação em Geografia. Niterói: UFF.

LIMA, Maria do Socorro Bezerra de. (2008). Políticas Públicas e território: uma discussão sobre os determinantes da expansão da soja no Sul do Amazonas. Tese de Doutorado. Rio de Janeiro: Programa de Pósgraduação de Ciências Sociais em Desenvolvimento, Agricultura e Sociedade-CPDA/UFRRJ.

PAULILLO. Luiz Fernando. (2000). Redes de Poder \& Territórios Produtivos. São Carlos: RIMA/UFSCAR.

SILVA, Carlos Alberto Franco da. (2003). Grupo André Maggi: corporação e rede em áreas de fronteira. Cuiabá: Entrelinhas, 2003.

SILVA, Carlos Alberto Franco da; SANTOS, Arthur Pereira; NASCIMENTO, Luciano Bomfim. (2011). Ensaio sobre o conceito de rede política territorial. In; SILVA, Carlos Alberto Franco da (org). Redes Políticas Territoriais: estratégias, conflitos e violência. Rio de Janeiro: Livre Expressão, pg. 15-34.

SILVA, Carlos Alberto Franco da. (2010). Redes políticas do agronegócio da soja na Amazônia. . In: SILVA, Carlos Alberto Franco \& 
NASCIMENTO, Luciano Bomfim do. Redes Políticas do Agronegócio da Soja: interesse, estratégia e resistências. Rio de Janeiro: Live Expressão, pg. 45-102.

SILVA, Carlos Alberto Franco da. (2011). As redes políticas do Grupo AMAGGI. Rio de Janeiro: Livre Expressão, 2011.

Data de submissão: 10/07/2012

Data de aprovação: 26/11/2013 